war. It is the natural tendency of all medical officers to clear out their hospitals by sending home the sick with too little discrimination; unless this is checked, the fighting strength of an army will soon fall off." How will this be if medical practitioners unused to the habits of soldiers are called upon to act instead of army surgeons?

In most European armies the medical officers seem to be treated with the respect and distinction due to their profession and military status. In Russia a title of high nobility was recently conferred on the chief of the Army Medical Department, and only the other day the Grand Cross of the Legion of Honour, the highest distinction in France, was given to a medical officer on his retirement from active service (Médecin Inspecteur-Général Didiot), amid the congratulations of officers of all branches of the service. Had he been a field-marshal, the French Government could not have given him a higher decoration. Such honourable distinctions give a prestige to the whole medical service, and are calculated to animate every medical officer to increased zeal in discharge of his military and medical duties.

It would be of immense advantage if the good feeling and impartiality which prompt from time to time such tributes to the worth of the medical profession in other countries were extended in a like degree to the members of the profession in Great Britain.

\section{ROYAL COLLEGE OF PHYSICIANS.}

AN extraordinary meeting of the Fellows was held on Wednesday, April 17th. The President, Sir AxDREW Crank, Bart., was in the chair.

A communication was received from the Colonial Office, asking for precise information as to the period of incubation of yellow fever, cholera, and variola, with a view to determining questions of quarantine. Sir Joseph Fayrer,Dr. Balfour, Dr. Cayley, and Dr. Thorne Thorne were appointed a committee to draw up a report on this matter.

A communication was also received from the promoters of an International Congress on Hygiene and Statistics, which is to meet in London in 1891, asking the co-operation of the College. This was granted, and Dr. Thorne and Dr. Ballard were selected to represent the College on the committee which is making the arrangements for this Congress.

A report was received from the committee appointed to consider whether, and in what way, the fever hospitals of the Metropolitan Asylums Board can be made available for clinical study. The committee reported that this was highly desirable, and could probably be effected. On the motion of Dr. WILKs, seconded by Dr. PAVY, it was resolved that a copy of the report should be sent to the President of the Local Government Board, and that the President of the College should seek an informal interview with him for a discussion of this subject.

A report was received from the Leprosy Committee, referring especially to the question of the communicability of leprosy, and to that of compulsory segregation. The committee had perused the documents forwarded to the College by the Government, on these subjects, but, in the absence of a full and scientific investigation of the subject, they did not feel able to offer any further recommendation on the question of compulsory segregation. They recommend that the College should again express its readiness to institute and direct, on behalf of the Government, the necessary inquiries for obtaining further reliable information on the question of the communicability of leprosy, whether by ordinary contact, inoculation, or any other channel, representing at the same time that any such scientific investigation would entail expense, and require considerable time. The adoption of this report was moved by Dr. Symes THompson, who spoke of the extension of leprosy in South Africa (which he had recently visited), and seconded by Dr. HANDFIELD JoNEs. The matter was again referred to the committee, in order that they might draw up a report as to the measures that would be required for obtaining adequate information on the subject, so that a detailed scheme may be submitted for the consideration of the Government.

A report was also received from the Commiteee on "Black-water Fever," a form of malaria found on the Gold Coast and elsewhere, in which the urine is dark-coloured from hæmorrhage. A copy of the report was directed to be sent to the Government.

\section{MEDICAL PARIS OF TO-DAY. BY ERNEST HART. \\ XVI.}

Ophthalmology in Paris . Clinic of Professor Panas: De Wecker's Operation for Ablation of the Lachrymal Gland: Capsular Advancement: Equatorial Puncture of the Sclerotic: Clinic of the Quinze-Vingts: M. Landolt's Clinic: Muscular Advancement in Treatment of Strabismus : Defective Motility Operative and Didactic Courses.

PARIS now presents at least as many advantages for the study of ophthalmology as the other great cities of Europe. The "official teaching"-that is to say, that which is given in the general hospitals of Paris and under the auspices of the Faculty-is of recent date, at least as a special branch of instruction. Formerly diseases of the eyes were treated as part of the general domain of of the surgery of the wards, with results which were admittedly unsatisfactory, and which I do not hesitate to describe as deplorable.

The chair of Ophthalmology of the Faculty of Medicine was founded ten years ago (1879). It is occupied by M. Panas, and is installed at the Hôtel Dieu. It includes the titular professor, a chef de clinique and his assistant or sub-chief, three housesurgeons, and six dressers elected by examination; a chief of the special laboratory, and, this year, an assistant professor have been attached to the clinic. The clinical service includes forty beds for males and twenty-four for females, of which four are nursery beds for the use of newborn and very young infants. There is "a laboratory of histology, bacteriology, and physiology," and a daily out-patient department. Every Wednesday there is a lesson in ophthalmoscopy for the students; twice a week (Monday and Friday) clinical lectures and operations on the in-patients by the professor; during the winter session, practical courses on refraction by the chef de clinique; during the summer session, conferences on the histology of the eye, normal and pathological (with illustrative lantern slides), by the chef de laboratoire; and further, a course of operative exercises. The latter course, which has hitherto been carried on by the titular professor, will henceforth fall to the assistant professor, who will hold office for nine years. The results of the work of the clinic and the laboratories appear in the Archives of Ophthalmology, founded by Panas and Landolt, and still continued, with the collaboration of Gayet of Lyons and Bardal of Bordeaux.

By the side of the clinics maintained by the State there exist private clinics, which have had and have great influence on teaching and progress. The most celebrated in earlier days were those of Desmarres, Sichel, and Liebreich, which were the rendezvous of European ophthalmologists, where all of us have found something to learn, and where von Graefe and Horner did not disdain to come for instruction. There are many of them at present; especially should be mentioned those of de Wecker, Landolt, Meyer, Galezowski-all of them competent and accomplished men. De Wecker and Landolt take the lead by their scientific reputation and the originality of their work.

The clinic of $M$. de Wecker is one of the most important in Paris. About 6,000 new patients are treated annually. These afford abundant material for the delivery of courses of lectures which are very interesting, and are followed by a considerable number of students and physicians of all countries. The clinical lectures, which are followed by the most various operations, are given at 3 o'clock on Monday, Wednesday, and Friday. Among these operations are some which are especially attractive to visitors, by reason of their novelty. Such is the operation for capsular advancement, which, in the opinion of $M$. de Wecker, is destined to replace muscular advancement in the majority of cases. It must, indeed, be acknowledged that the result is absolutely identical; the capsule is detached above and below the muscle which is to be advanced, and the sutures, while producing a fold of the tendon of the muscle, produce, when they are fastened, a forward traction of the muscle, such as would have been obtained by detachment of the insertion of the tendon. In fact, capsular advancement is nothing less than muscular advancement without section of the tendon, which so far simplifies the operation, and renders it notably less laborious. Another quite recent operation consists in ablation of the lachrymal gland, with the object of arresting lachrymation when the cure has not been obtained by the classic treatment with bougies. The excision of this palpable portion of the lachrymal gland is very simple as an operation, and it is sufficient to 
lessen the lachrymal secretion to a very great extent. It therefore affords a valuable resource in the treatment of rebellious cases which have often been the despair of ophthalmologists, and which weary the patience of the sufferer. Another interesting series of operations are those of equatorial puncture of the sclerotic, for glaucoma in those cases in which the operations habitually practised on the anterior chamber-sclerotomy and iridectomy-have not given the expected results. This, however, is a very old procedure in this country, and was a favourite one with Zachariah Lawrence. Among the most noteworthy publications of the clinic of the Rue du Cherche Midi must be mentioned the Traite Complet des Maladies des Yeur.

The ophthalmological clinic of the Quinze-Vingts, another ophthalmological institution which deserves a visit, was founded in 1881 by $M$. Fieuzal, and in 1886 M. Trousseau was also appointed. On the death of its founder in July, 1888, it was reorganised, and it includes now two distinct services entrusted to MM. Abadie and Trousseau, who give alternately consultations on ocular diseases three days a week. The other three days are given up to operations arising out of the consultations. Each service includes thirty-three beds, and, besides the chef de service, there is an assistant physician, M. Valude, with $M$. Abadie, and M. Chevallereau with M. Trousseau, and two house-surgeons who undertake the preliminary examination of the patients and their subsequent care. Besides the operations and consultations, the surgeons attached to this clinic give every day conferences and clinical lectures, which are attended by a considerable number of French physicians and students as well as visitors. The housesurgeons also give technical explanations in various subjects of ophthalmology. To the clinic is attached a histological laboratory for the study of the specimens proceeding not only from the operations, but also from post-mortem examinations practised on the patients of the blind asylum of the Quinze-Vingts. This laboratory possesses at present about 2,000 specimens which have been and are capable of being utilised, from the point of view of scientific research; it is open to foreign students. It comprises, further, two other rooms reserved, one for the museum containing microscopical and other preparations relating to the pathology of the eye ; and the other a laboratory of bacteriology founded last year, in which already some useful researches have been carried out. Seventy-three thousand patients have been treated at this clinic since its foundation in 1881, and its statistics indicate its value and extent. In $1887,1,800$ operations were practised here, 518 of which were for cataract, and 48,000 consultations were given. This year the number of consultations has risen to 53,600, which included 2,167 operations, among which were 622 for cataract.

The clinic of Dr. Landolt, situated at 27, Rue St. André des Arts, is frequented daily by from 60 to 100 patients. M. Landolt, assisted by two surgeons, attends there very regularly every day from noon till 2 o'clock. He operates twice a week, Wednesday and Saturday, and the operations are followed by conferences and demonstrations intended for practitioners and students. These lectures deal with the most varied subjects, the clinical and practical point of view predominating; and the presentation of interesting cases serves always to afford information such as theoretical lectures alone are often incapable of giving. The different territories of ophthalmology are successfully explored in this way, and there is a considerable collection of microscopic preparations which $M$. Landolt places at the disposal of his pupils, in support and explanation of the demonstrations. One of the domains of ophthalmology which he has especially explored is that of the movements of the eye, studied from the physiological as well as from the pathological point of view. The importance and originality of the views of $\mathrm{M}$. Landolt in all that concerns strabismus are well known. The etiology of that affection, the conditions which preside over its evolution, and the means of curing it, are very carefully studied. Each patient suffering from any defect whatever of the motility of the eye, is subject to complete examination, not only with reference to refraction and visual perception and the degree of strabismus, but also to the relative strength of each muscle and the degree of binocular vision. Ingenious methods and special apparatus are employed for illustrating these different points. I would especially draw attention to the methods employed in determining the fields of fixation or excursion of the eyes, so important from the point of view of prognosis and of operative indication. In relation to the treatment of strabismus and the muscular affections, Dr. Landolt combines the muscular orthop tic cure (stereoscopic apparatus of Hering) with the surgical cure. His researches on the relative force of muscles by means of the field of fixation have led him to prefer muscular advancement to tenotomy; he was one of the first and warmest supporters of this operation-more difficult, indeed, but more sure and now more generally approved.

The arguments which weigh in favour of muscular advancement were very clearly put forward by $M$. Landolt lately at the International Congress of Ophthalmology of Heidelberg, and the following figures which I extract from that report are very convincing in this regard.

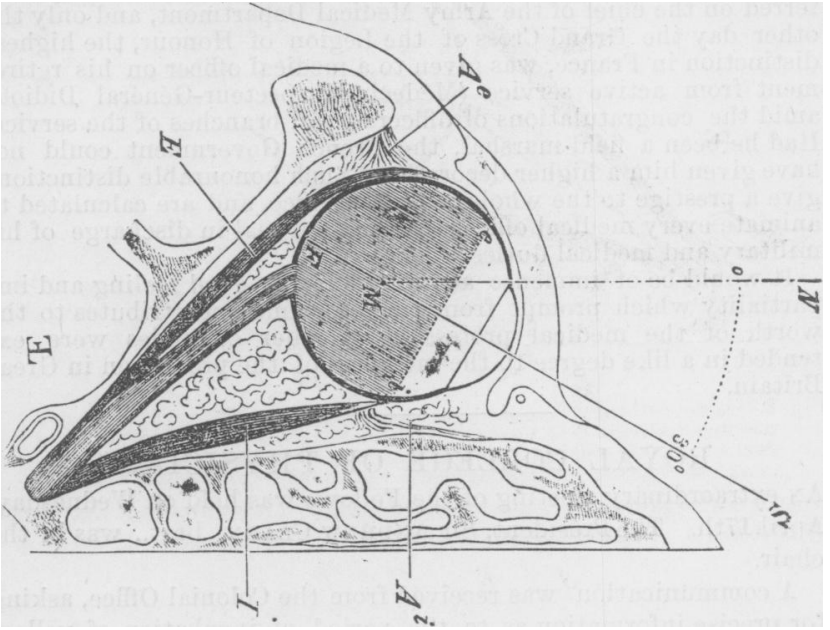

Fig 1.-Convergent strabismus of the left eye ; respective situation of the rectus internus in active tension; the externus passively lying around the globe.

M. Landolt also affords at his clinic opportunities for studying the subject of insufficiency of convergence and defective motility, which the author considers as a first step towards a latent divergent strabismus. He has applied himself to the surgical cure of this affection, for which he recommends muscular advancement of the internal rectus in preference to tenotomy or setting back of the external rectus. The following schema, which

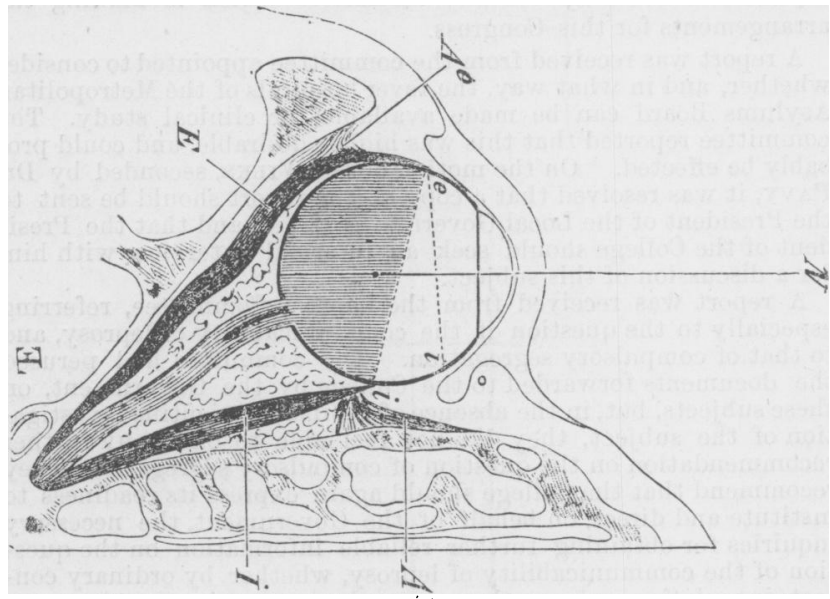

Fig. 2.-Tenotomy of the rectus internus, having produced retraction of the rectus internus from $i$ to $i^{\prime}$, and relaxation of the rectus internus, which is much less drawn over the globe. The action of the two muscles is weakened.

1 take also from his recent report on the subject, shows the good results of operative intervention such as he practises. In this schema are represented amplitudes of convergence of the abscissæ of the metric angles. The line $o o$ corresponds to the parallelism of the lines of vision; the part situated marked with the sign + represents positive convergence (the convergence properly socalled); the part above the line zero marked with the - sign represents the negative convergence or divergence.

Thus the schema $A$ of Figure 4 represents the amplitude of 
medium convergence where there is one metric angle of divergence and nine metric angles of convergence.

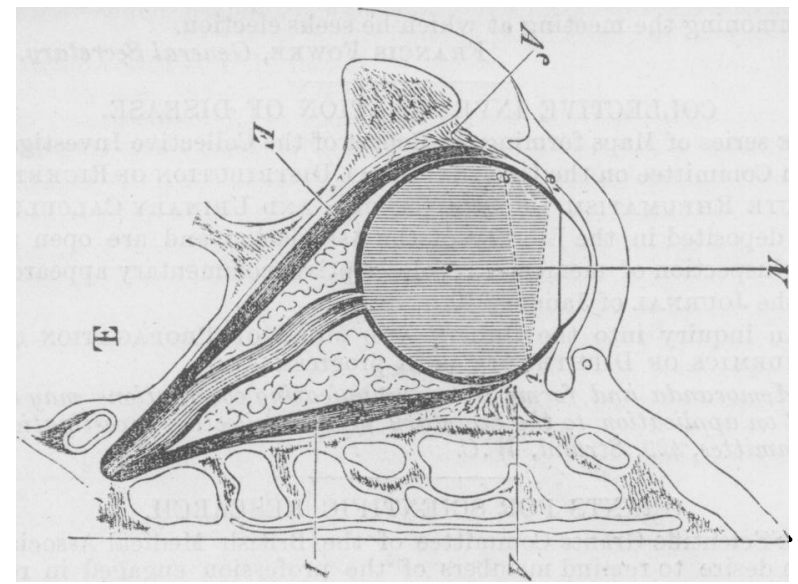

Fig. 3.-Adrancement of the external rectus. The insertion of the rectus nternus has not been changed, that of the rectus externus advanced from $e$ to $e^{\prime}$. The strength of this muscle is increased, while that of its antagonist has not undergone any diminution.

B C D corresponds to cases of insufficiency of convergence without (B), or with (C) augmentation of the forces of divergence (abduction

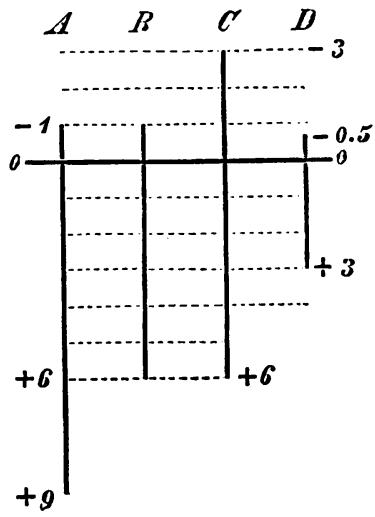

Fig. 4.-Schema of con zergense.

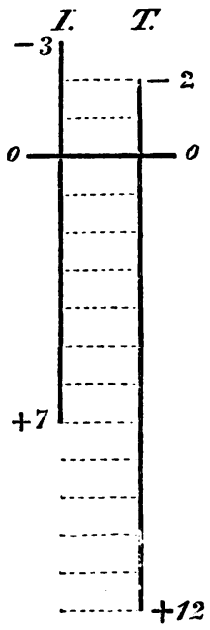

Fig. 5. - Fffect of a tenotomy. I. Amplitude of insufficient convergence. T. Amplitude of the same person rendered normal by tenotony of rectus

or negative convergence), and with reduction of amp.itude at its two extremities (D).
Together with numerous operations of strabismus, of cataract, glaucoma, etc., M. Landolt practises a considerable number of T. $A$.

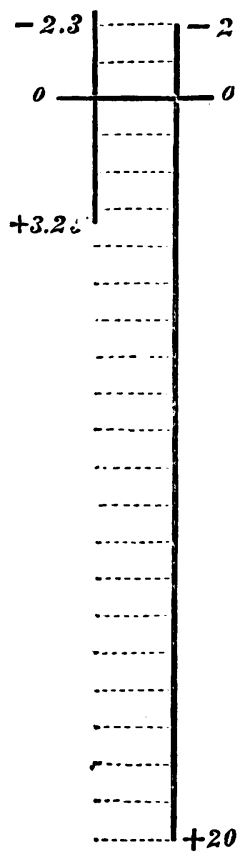

Fig. 6.-Effect of an advancement I. Amplitude of very insufficient con. vergence. A. Amplitude of convergence of the same person after advancement of rectus internus.

operations on the eyelids. The surgical cure of trichiasis, of ectropion and entropion, has been modified by him in an original fashion. For ectropion and implantation of the eyelashes he has recently employed a sufficiently simple and efficacious procedure, which consists in the formation of two triangular flaps in the direction parallel to the free border of the eyelid. The one includes the eyelid which is to be set straight; the other, of the same form and dimensions, is formed only by the skin of the eyelid. It suffices to slide the second flap under the first to obtain a free border deprived of lashes. Other ingenious proceedings are employed for autoplastic operations on the eyelids. Besides the methods by sliding flaps borrowed from neighbouring parts, he has employed with success Reverdin's grafts, and quite lately has replaced this latter method by the skin graft of Thiersch, consisting in the implantation on a non-granular surface of a very thin flap of skin detached with a razor. In a case of exceedingly destructive epithelioma of the lower lid, flaps, about two centimetres long and three to four centimètres wide, were borrowed from the thigh, and were transplanted on to the site of the loss of substance. They became attached with such rapidity that eight days afterwards the extensive wound was completely covered over.

In addition to the clinical teaching, $M$. Landolt gives a course of operations on the subject or on the eyes of animals, and, as he speaks English fluently, English students are enabled to profit by his private operative courses given in that language.

Amongst his numerous publications may be cited those on the employment of instruments in ophthalmic surgery, which have been translated into English, such as "A New Procedure of Blepharoplastic and Optico-ciliary Section:" "Some Operations Practised on the Eyelids ;" "Tenotomy of the Inferior Oblique," etc. A considerable number of publications have issued from this clinic during the last ten years; the most important work is the Accommodation et Refraction, which has been translated into English : an analogous work on the methods of exploration of the eye; one on the disorders of motility, and the classical Traite Complet d'Ophthalmologie, of which he is joint author with De Wecker, and which is still in course of publication. His lectures on the diagnosis of diseases of the eyes, given at the Ecole Pratique, have also been translated into English. They give an excellent 
account of the principles which should guide the practitioner as well in the domain of refraction and optics as in that of clinical treatment.

In M. Landolt's clinic is not only produced work of pure speciality, but certain questions of general pathology are al so studied there, in their relations to diseases of the eye. Thus quite lately M. Landolt published, on the occasion of the jubilee of Donders, an important study of verbal blindness, Cecité Verbale, in which will be found the relation of three interesting cases complicated with hemiachromatopsy.

\section{THE MEDICAL SICKNESS, ANNUITY, AND} LIFE ASSURANCE SOCIETY.

Quarterly Meeting; Number of Claims made; Increase of Annual Income; First Valuation of Investments; Increase of Capital Account; Actuary's Opinion of the Favourable Financial Position of the Society.

Av important and interesting meeting of the Medical Sickness, Annuity, and Life Assurance Society was held on Wednesday, April 17th, at 38, Wimpole Street, under the Presidency of Mr. ERnest Hart. There were present Mr. J. Brindley James, Dr. Major Greenwood, jun., Dr. R. Lord, Dr. F. S. Palmer (of East Sheen), Mr. W. J. Stephens (of Brighton), Dr. J. W. Hunt, and Mr. F. Wallace. Mr. S. W. Sibley, Dr. W. Bruce (Dingwall), Dr. W. M. Ord, and Dr. F. De Havilland Hall were prevented from being present by their engagements.

From the quarterly report read to the meeting, it appeared that the progress of the Society had been fully maintained, and its operations had been of a valuable and satisfactory character. The sickness experienced and compensated, though well within the rate anticipated in the tables, had been considerable-as many as sixteen claimants having been paid in one week, and over sixty guineas a week paid for two or three in succession. The illnesses included some of a very serious nature, as locomotor ataxy, chronic myelitis, iritis, and gangrene of the lung; and others of a minor character, as measles and whooping-cough. There had as well been payments on account of several cases of disablement arising from accidents. During the quarter, forty-one new members had joined, and the effective membership had risen above 950. The annual premium income was stated to be over $£ 10,000$ a year, that to the sickness fund alone being over 100 guineas per week, while the entire working expenses of the Society were under $£ 500$ a year. The total funds of the Society on March 30th amounted to $£ 30,638$, an increase of $£ 1,919$ in three months, and of $£ 8,035$ in twelve months. Of this sum $£ 30,263$ is invested on behalf of the members in the names of the four trustees-Sir $T$. Spencer Wells, Bart., Mr. Ernest Hart, Dr. W. M. Ord, and Mr. J. R. Upton.

The first quinquennial valuation of the affairs of the Society was produced. This has been made by Mr. F. G. P. Neison, the eminent actuary. The results are fery satisfactory, the sickness rate having been found to be but 67 per cent. of the expectation, and the mortality even more favourable. $A$ large financial surplus is the gratifying result, and though the actuary is naturally apxxious to guard against premature allocation of the surplus, he speaks in high terms of the efficiency with which the Society's affairs have been conducted, and warmly congratulates the members on the pronounced success it has achieved. Information as to the Society, with printed particulars, proposal forms, etc., will be supplied free of cost on application to the Secretary, Mr. C. J. Radley, 26, Wynne Road, Brixton, London, S.W.

\section{ASSOCIATION INTELLIGENCE, NOTICE OF QUARTERLY MEETINGS FOR 1889. ELECTION OF MEMBERS.}

Mreminfas of the Council will be held on July 10th, and October 16th, 1889. Candidates for election by the Council of the Association must send in their forms of application to the General Secretary not later than twenty-one days before each meeting, namely, June 20th, and September 26th, 1889.

Any qualified medical practitioner, not disqualified by any bylow of the Association, who shall be recommended as elicible by any three members, may be elected a member by the Council or by any recognised Branch Council.
Candidates seeking election by a Branch Council should apply to the Secretary of the Branch. No member can be elected by a Branch Council unless his name has been inserted in the circular summoning the meeting at which he seeks election.

FrıNCIs Fow Kx, General Secretary.

COLLECTIVE INVESTIGATION OF DISEASE.

THE series of Maps forming the Report of the Collective Investigation Committee on the Geographical Distribution of Rickets, acute Rheumatism, Chorea, Cancer, and Urinary Calculdo are deposited in the Library of the Association, and are open to the inspection of members. A descriptive commentary appeared in the JoUnNaL of January 19th, 1889.

An inquiry into the Origin and Mode of Propagation of EPIDEMICS OF DIPHTHERIA is in progress.

Memoranda and forms for communicating observations may be had on application to the Secretary of the Collective Investigation Committee, 429, Strand, W.C.

\section{GRANTS FOR SCIENTIFIC RESEARCH}

THe Scientific Grants Committee of the British Medical Association desire to remind members of the profession engaged in researches for the advancement of medicine and the allied sciences, that they are empowered to receive applications for grants in aid of such research. Applications for sums to be granted at the next annual meeting should be made without delay to the General Secretary, at the office of the Association, 429, Strand, W.C. Applications must include details of the precise character and objects of the research which is proposed.

Reports of work done by the assistance of Association grants belong to the Association.

Instruments purchased by means of grants must be returned to the General Secretary on the conclusion of the research in furtherance of which the grant was made.

\section{BRANCH MEETINGS TO BE HELD.}

Metropolitan Counties Brancit : Westary District.-A meeting will be held on Wednesday, May 22nd, at the Royal India Asylum. Faling Common, by kind permission of Dr. Christie, C.I.E. The chair will be taken by Dr. Brodie Sewell, the President of the Branch, at 8.30 P.M. A discussion on Brodie Sewell, the President of the Branch, at, 8.30 P.M. A discussion on
Cremation will be opened by Sir Spencer Wells, Bart. J. Swinburne Hanham Cremation will be opened by Sir Spencer Wells, Bart. J. Swinburne Hanham, Esq., J.P., Honorary Secretary of the Cremation Society. and other gentlemen, any lady or gentleman introduced by a member of the Branch.-C. A. PATTEN, Honorary Secretary, Marpool House, Ealing.

South-Fastern Branch : EAST Sussex District.-A meeting of the above District will be held at the Calverley Hotel. Tunbridge Wells, on Thursday, May 23rd. Dr. Johnson will preside. The Chairman will read a case of $\mathbf{M y x}$ cedema. Gentleman desirous of reading papers or showing cases should communicate with the Honorary Secretary, T. JENNER Verrale, $9 \overline{7}$, Montpellier Road, Brighton.

South-Eastern Branch : East SuRrey District.-The next meeting of this District will be held at the Greyhound Hotel, Croyclon, on 'Thursday, 9th, at 4 P.M., Walter Rosser, M.D., of Croydon, in the chair. Dinner, 6 P.M. charge, is , exclusive of wine. The following papers, etc are promised. Dr. Goodhart: On some cases of Transient Glycosuria of Neurotic Origin. Dr. William Duncan: On the Importance of Systematically Examining the Abdo men in Affections of the Female Pelvic Organs. $-T$. T. DUNCAN, iT. D. Honorary Secretary, Park House, Croydon.

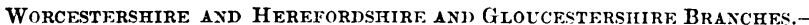
A combined meeting of these Branches will be held at the Star Hotel, Worcester, on Tuesday, May 7 th, at 3.15 P.M.; dinner at 6 . Business : Mr. W. Moose (Stourport) : A short paper on Two Evils Seriously A ffecting the Welfare of Medical Practitioners. Dr. Haynes (Malvern): The College of Surueon and Its Members. Dr. Broadbent will give an address on the Circulation in Diseases of the Kidney.

ABSTRACT OF PROCEEDINGS OF COUNCIL.

Aт a numerously attended meeting of the Council, held in the Council Room at the offices of the Association, 429, Strand, W.C. on Wednesday, April 17th, 1889, Dr. Bridiwater, President of the Council, in the Chair, it was

Resolved: That the financial statement for the year ending December 31st, 1888, as certified by the auditors, be approved and published in the JourNaL, in accordance with By-law 26.

The remainder of the proceedings of the Council will appear in next week's JoURNAL. 